\title{
ANÁLISIS CRÍTICO DE UN ESTADO DE ALARMA EXCEPCIONAL: LA COVID-19 Y EL DERECHO DE EXCEPCIÓN
}

\author{
Alfonso Cuenca Miranda \\ Letrado de las Cortes Generales
}

Cómo citar este artículo / Citation: Cuenca Miranda, A. (2021). Análisis crítico de un estado de alarma excepcional: la covid-19 y el derecho de excepción. Garrido López, C. (coord.) Excepcionalidad y Derecho: el estado de alarma en España, Colección Obras colectivas, Fundación Manuel Giménez Abad, Zaragoza. DOI: https://doi.org/10.47919/FMGA.OC21.0008

SUMARIO: I. INTRODUCCIÓN. II. LA RESPUESTA ESPAÑOLA ANTE LA CRISIS: UNA ALARMA "EXCEPCIONAL". III. REFORMAS PARA EL FUTURO

\section{INTRODUCCIÓN}

El conocido como SARs-CoV-2 ha cambiado el mundo. Ha supuesto la amenaza más importante para la especie humana en los últimos ochenta años. Históricamente, las sociedades se veían periódicamente asoladas por enfermedades infecciosas que provocaban una gran mortandad: desde la peste negra de 1348 a la fiebre española de 1918. La gran diferencia en esta ocasión se ha debido, se debe, a que la nueva pandemia se produce en un mundo globalizado, lo que provoca que su expansión se acelere vertiginosamente en términos temporales y espaciales $\mathrm{y}$, por otra parte, que sus consecuencias a medio y largo plazo en el contexto mundial sean de muy hondo alcance.

El Derecho, en cuanto genial invención humana como instrumento para encauzar y resolver el conflicto social, ha aparecido desde el primer momento compelido a dar respuesta a la nueva situación. Y así, en cuanto que las medidas a adoptar para contener la expansión y efectos de la pandemia 
comportaban necesariamente una alteración radical de nuestro modelo de convivencia, la realidad llamaba insistentemente y con urgencia a las puertas del Derecho para la articulación de esa respuesta ante el mayor desafío al que el mismo se enfrentaba desde hace mucho tiempo. De hecho, este ha sido el mayor reto que han afrontado democracias consolidadas como las occidentales, toda vez que los dos grandes conflictos del siglo XX se habían presentado ante regímenes que solo con mucha generosidad (salvo el caso británico probablemente) podían ser calificados como plenamente democráticos.

Y llegó el momento de desempolvar manuales que explicaban qué hacer cuando todo parece perdido. El viejo derecho de crisis fue rescatado del olvido. $Y$ muchos parecieron sorprenderse ante el hecho de que en numerosos casos el derecho daba una respuesta, por imperfecta que fuera, a situaciones como la vivida. Eso sí, faltaba adaptarla a nuestras sociedades post-modernas altamente "tecnologizadas".

Como es sabido, el derecho articulado para tales momentos es conocido como derecho de excepción, pues excepcional es la situación a la que responde y excepcionales han de ser las respuestas establecidas por el mismo. Frente a lo que subyace en cierto imaginario colectivo, particularmente en el español, el derecho de excepción no sólo no es incompatible con la democracia, sino que aparece como una garantía más, si cabe reforzada, de supervivencia del propio régimen democrático. Así, ha sido calificada como una garantía diacrónica de la propia Constitución ${ }^{1}$, pues permite su supervivencia en situaciones temporales donde la misma aparece seriamente amenazada. Ahora bien, ese fin mayor implica y exige sacrificios para el propio sistema constitucional, de tal modo que (al igual que ocurre con ciertos tratamientos agresivos en medicina que conllevan un empeoramiento transitorio del paciente de cara a su salvación, coma inducido, como ejemplo destacado de ello) el derecho de excepción supone el desplazamiento temporal de la vigencia de determinadas normas constitucionales, en especial, en lo que respecta a la distribución y limitación del poder, pues la emergencia requiere cierta concentración del mismo para dar una respuesta eficaz, y a la plena vigencia de los derechos, fundamentales o no, reconocidos en la Constitución.

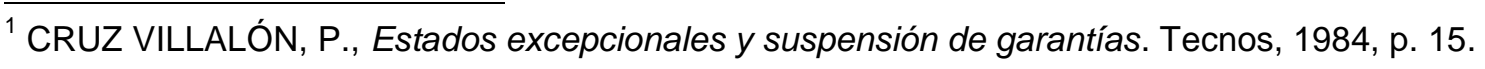


El ordenamiento jurídico español se inscribe en aquellos que han optado por constitucionalizar la excepción, por encauzarla jurídicamente al máximo nivel (entre los que cabe situar también al portugués ${ }^{2}$, el griego ${ }^{3}$, el holandés ${ }^{4}$ o el finlandés ${ }^{5}$ ) frente a otros modelos que desconocen la excepción a nivel constitucional, renunciando a regularla (caso paradigmático británico o belga ${ }^{6}$ ), o que se enfrentan a la misma previendo únicamente la concentración de poder en una magistratura a la que se atribuyen en tales casos poderes amplios pero indeterminados (modelo de dictadura comisoria o constitucional, del que sería prototípico el artículo 16 de la Constitución francesa de 1958). A los señalados y clasificados tradicionalmente por la doctrina cabría añadir un tertium genus (en este caso un cuartum) que englobaría a aquellos ordenamientos en los que se alude constitucionalmente a la emergencia, aunque de manera muy parcial o fragmentaria (casos italiano y alemán, cuyas Nomas fundamentales ${ }^{7}$ regulan las respuestas frente a agresiones armadas, con inclusión de algunos aspectos de la afección de derechos y libertades, refiriéndose a otros supuestos de emergencia únicamente desde el punto de vista de su repercusión en la distribución de competencias). Como más adelante se insistirá, hemos de subrayar que la opción del constituyente hispano de 1978 fue un auténtico acierto (pesando en ello las tristes experiencias de nuestro pasado, reciente y no tanto), ya que, si bien podría aducirse que prever lo imprevisible es un esfuerzo en gran parte estéril, sin embargo, el hecho de que la propia decisión política fundamental recaiga sobre los mecanismos de defensa de la Constitución ante situaciones de crisis, y, lo que es igual de importante, los aspectos que en aras a ello nunca podrán ser sacrificados sin que con ello pereciera la propia Ley de leyes, supone una garantía reforzada de nuestro modelo de convivencia. La experiencia vivida en nuestro país en los últimos meses así lo atestigua, con todas sus imperfecciones, cuando no crasos errores, tal y como se expondrá.

\footnotetext{
${ }^{2}$ Artículo 19 de la Constitución.

${ }^{3}$ Artículo 48 de la Constitución.

${ }_{5}^{4}$ Artículo 103 de la Constitución.

${ }^{5}$ Artículo 23 de la Constitución.

${ }^{6}$ En Reino Unido, como es sabido, en virtud del dogma de la soberanía parlamentaria, la excepción se "regula" a posteriori, con la tramitación parlamentaria del correspondiente Indemnity Bill que, en caso de aprobación, exonera de responsabilidad al ejecutivo por las medidas adoptadas durante la crisis. Por lo que respecta al caso belga, cabe recordar que su Norma Fundamental (art. 187) establece que en ningún supuesto podrá suspenderse la Constitución total o parcialmente.

7 Artículos 78 y 120 de la Constitución italiana y artículos 35,87 a) y 115 de la Ley Fundamental de Bonn.
} 
Ante la crisis sin precedentes provocada por la irrupción de un virus devastador, la opción de los poderes públicos españoles, principalmente del ejecutivo, en decisión posteriormente validada o ratificada por el Congreso de los Diputados, ha sido el acudir al derecho excepcional establecido en la Constitución. Si bien en los primeros días de marzo fueron algunas Comunidades Autónomas las que, en virtud de la atribución de competencias sectoriales, adoptaron medidas en relación con determinados ámbitos insertos en su competencia (educación, ordenación de los servicios y locales de restauración a la cabeza), pronto se fue consciente de que se estaba ante algo completamente desconocido en cualquier experiencia contemporánea, que suponía un auténtico reto para la propia supervivencia de la comunidad o, como mínimo, de una parte relevante de esta (la denominada población vulnerable), y que exigía medidas drásticas (provocadoras de otros males) para afrontarlo. Medidas por cuyo carácter gravoso e intensidad sólo podían adoptarse en el marco del derecho excepcional establecido por el constituyente y el legislador orgánico de 1981.

Y, como se insistirá con posterioridad, ello debe considerarse un acierto. La gravedad de la situación y, en especial, la intensidad con que las respuestas o medidas exigidas por la misma han incidido en la esfera de los derechos y libertades ciudadanos así lo aconsejaba. Cierto es que, como se ha afirmado, en otros países no se ha seguido la misma vía, incluso en algunos que contaban con mecanismos semejantes al español. Con todo, han de hacerse matizaciones a tal extremo ${ }^{8}$. Así, por ejemplo, Portugal siguió en las semanas más duras de la pandemia un procedimiento semejante al español ${ }^{9}$. Por otra parte, si bien se ha señalado que países como Italia o Alemania no han optado por la declaración del estado excepcional, ello es así por cuanto que sus ordenamientos no contemplaban la emergencia en los términos establecidos en

\footnotetext{
${ }^{8}$ Véase BINDER, K., et alii. States of emergency in response to coronavirus crisis: situation in certain Member States. European Parliament Research Service, mayo 2020.

${ }^{9}$ Así, el 18 de marzo de 2020 el Presidente de la República declaró el estado de emergencia constitucional, que fue prorrogado hasta el 2 de mayo. A partir de dicha fecha se pasó a hacer frente a la pandemia mediante la declaración por el Gobierno del estado de calamidad previsto en la legislación de protección civil. Ha de tenerse en cuenta que la Constitución portuguesa sí acoge expresamente una concepción gradualista de los estados excepcionales, de tal modo que el estado de excepción se adoptará cuando las condiciones que dan lugar al de emergencia sean más graves. Por otra parte, y como diferencia fundamental respecto al sistema español, en el estado de alarma se permite expresamente la suspensión de algunos derechos, libertades y garantías (art. 19.3 de la Constitución).
} 
el nuestro ${ }^{10}$. Por lo que respecta al caso francés, se ha renunciado a acudir a la dictadura comisoria del art. 16 de su Carta Magna, y se ha optado por regular en ley orgánica un estado de urgencia o emergencia sanitaria diferenciado del estado de urgencia "ordinario" regulado en la década de los cincuenta ${ }^{11}$ y aplicado en los sesenta y recientemente a raíz de los atentados terroristas de la pasada década ${ }^{12}$. Pero dicho estado de emergencia sanitaria no es sino un desarrollo y concreción del estado de urgencia general, no pudiéndose hablar en tal caso de legislación sanitaria ordinaria stricto sensu.

\section{LA RESPUESTA ESPAÑOLA ANTE LA CRISIS: UNA ALARMA "EXCEPCIONAL"}

Como es de sobra conocido, en España el Gobierno se decantó finalmente por declarar el estado de alarma mediante Real Decreto 463/2020, de 14 de marzo. Se invocó a tal efecto lo establecido en el artículo 4 de la LO 4/1981, de 1 de junio, de los estados de alarma, excepción y sitio, en su apartado b), al considerar que el presupuesto de hecho contemplado por este ("crisis sanitarias, tales como epidemias y situaciones de contaminación graves")

${ }^{10}$ En Italia la Constitución regula expresamente el estado de guerra (art. 78), y alude de manera indirecta a la asunción por el Estado central de competencias regionales y locales en supuestos de peligro grave para la incolumidad y seguridad públicas (art. 120). Como es conocido, en el país transalpino se ha recurrido durante la crisis del covid-19, no sin cierta controversia doctrinal y política, a la vía de los decretos-leyes y de decretos del Consejo de Ministros para hacer frente a la pandemia (en relación con los primeros, hay que recordar que, a diferencia del caso español, los decretos leyes son convalidados por ley, teniendo la derogación efectos ex tunc, salvo disposición en contrario, y, sobre todo, que los mismos pueden afectar a derechos fundamentales, no existiendo limitación material al respecto). En Alemania, la Ley Fundamental de Bonn únicamente regula de modo exhaustivo el denominado estado de defensa (art. 115 a.), en respuesta a agresiones armadas. En otros artículos se refiere a una suerte de estado de necesidad interna (arts. 35, 87 a. y 91), derivado tanto de catástrofes como de amenazas internas al orden constitucional, pero desde un punto de vista principalmente competencial, con la previsión de la posibilidad de adopción de medidas por parte del poder federal e intervención de las Fuerzas Armadas. En el caso del covid-19 han sido los Lander los principales protagonistas de las medidas adoptadas, admitiéndose en función de la virulencia de la pandemia o de aspectos afectados, la coordinación por los poderes federales.

${ }_{11}^{1}$ Ley no 55-385, de 3 de abril de 1955, modificada en 2011 y 2017.

12 El estado de urgencia sanitaria se ha introducido mediante su inserción en el Código de Salud Pública a través de la Ley no 2020-290, de 23 de marzo de 2020. Con todo, ha de tenerse presente que, en relación con el estado de urgencia, se ha planteado desde hace ya tiempo la necesidad de su reconocimiento a nivel constitucional, dada la importante afección que puede producir en los derechos de los ciudadanos. Así, cabe recordar que en el año 2015 se impulsó por el presidente Hollande la reforma del artículo 36 de la Constitución (que regula el estado de sitio como competencia del Consejo de Ministros) para introducir al máximo nivel normativo el estado de urgencia (ante las discrepancias de textos entre ambas Cámaras y el debate suscitado por la reforma, el Presidente puso fin al proyecto). 
coincidía con la situación afrontada. Sin embargo, las medidas adoptadas al respecto excedían con mucho las establecidas en la propia Ley Orgánica para dicho estado. Así, y como aspecto más destacable, se establecía (art. 7 del RD 463/2020) el confinamiento de la población en sus domicilios con excepciones muy tasadas que permitían cortos desplazamientos, incluso limitados en número de metros 0 kilómetros ${ }^{13}$, para la realización de determinadas actividades o trámites (compra de alimentos, farmacias...). Medidas en gran parte indiscutibles en cuanto a su necesidad para frenar la expansión de un virus que se estaba demostrando altamente letal y que, sobre todo, estaba colapsando los servicios sanitarios y por lo tanto imposibilitando la debida atención, en particular, en ciudades como Madrid y Barcelona. En este sentido, como se defendiera ya en fecha tan temprana como el 23 de marzo por el autor de las presentes líneas ${ }^{14}$, la medida suponía una auténtica suspensión de la libertad de circulación reconocida en el artículo 19 de la Constitución, suspensión sólo permitida en el marco del estado de excepción (y en el de sitio), pero en ningún caso bajo el estado de alarma, de conformidad con lo establecido por el artículo 55.1 de nuestra Constitución. La suspensión de la libertad de circulación implicaba, además, la suspensión de facto de otros derechos fundamentales, como el de reunión y manifestación ${ }^{15 y 16}$.

\footnotetext{
${ }^{13}$ Así sucedió cuando mediante la Orden del Ministerio de Sanidad de 30 de abril se permitió dar paseos "con una distancia no superior a un kilómetro con respecto al domicilio" (art. 2.4 Orden SND/380/2020).

${ }^{14}$ CUENCA MIRANDA, A., "Alarma ‘excepcional'". Papeles de la Fundación para el Análisis y los Estudios Sociales no 236, 23/3/2020. Doce días antes, el 11 de marzo de 2020, el mismo autor manifestaba en el diario $A B C$ ("El Derecho ante el coronavirus", La Tercera) que la que entonces era la situación epidemiológica encajaba "dentro de los supuestos que pueden dar lugar a la declaración del estado de alarma", para añadir más adelante que "en todo caso, no cabría descartar que ante una extensión muy amplia de la enfermedad-epidemia pudiera recurrirse a la declaración del estado de excepción. La duración temporal limitada del estado de alarma y la menor intensidad de las restricciones a la libertad de circulación así podrían imponerlo (hay que recordar que en el estado de alarma se habla de limitaciones a tal derecho, mientras que en el de excepción se permite la suspensión del mismo). En tal caso, la declaración seguiría correspondiendo al Gobierno nacional, si bien con la autorización previa del Congreso de los Diputados".

${ }^{15}$ Entre los autores que han defendido la procedencia de haber decretado el estado de excepción por suponer las medidas adoptadas, en particular, el confinamiento domiciliario, una suspensión de derechos, cabe citar a ÁLVAREZ GARCÍA, F. J., (Estado de alarma o de excepción. Tirant Tech., 2020), ARAGÓN REYES, M., ("Hay que tomarse la Constitución en serio". El País, 10 abril 2020), AMOEDO SOUTO, C., ("Vigilar y castigar el confinamiento forzoso. Problemas de la potestad sancionadora al servicio del estado de alarma sanitaria". El Cronista del Estado Social y Democrático de Derecho, 86-87, 2020, pp. 66-77), COTINO HUESO, L., ("Los derechos fundamentales en tiempos del coronavirus. Régimen general y garantías y especial atención a las restricciones de excepcionalidad ordinaria". El Cronista del Estado Social y Democrático de Derecho, 86-87, 2020, pp. 88-101) y DÍAZ REVORIO, F. J., (“A vueltas con la suspensión de los derechos fundamentales", Almacén de derecho, 9/4/2020).
} 
El confinamiento general de la población en sus domicilios (con excepciones muy tasadas) excedía con creces el margen de actuación de los poderes públicos en el estado de alarma, no siendo admisible su encaje en las limitaciones de acudir o permanecer en determinados lugares a determinadas horas incluidas en el elenco de medidas que puedan adoptarse bajo la vigencia del estado de alarma, de acuerdo con lo establecido en LO 4/1981 ${ }^{17}$. El estado de alarma "solo" permite la adopción de medidas limitativas o restrictivas de derechos fundamentales, $\mathrm{y}$, como resulta obvio, únicamente aquellas establecidas de antemano en la LO 4/1981. Las limitaciones de derechos que pudiesen establecerse bajo la vigencia de un estado de alarma no pueden afectar al contenido esencial de los mismos, ya que en tal caso nos hallaríamos ante una suspensión de aquellos ${ }^{18}$. Por ello, el artículo 11 de la LO 4/1981, al enumerar las medidas que pueden adoptarse en el estado de alarma, no contempla (ni puede contemplar) una medida como la adoptada, esto es, el confinamiento domiciliario (con excepciones muy tasadas), afectando de lleno a su contenido esencial. Resulta claro que, acogiéndose cualquiera de las definiciones del contenido esencial de un derecho o libertad ofrecidas por la doctrina de nuestro Tribunal Constitucional al respecto ${ }^{19}$, la medida señalada supuso una intervención a "corazón abierto" (y como tal necesaria, por lo demás, dada la patología a sanar) en el núcleo de la libertad de circulación reconocida constitucionalmente. ${ }^{20}$

\footnotetext{
${ }^{16}$ El voto particular formulado en la sentencia de 30 de abril de 2020 dictada por la Sección $1^{\text {a }}$ de la sala de lo Contencioso-Administrativo del TSJ de Aragón mantuvo la tesis de que el derecho de reunión y manifestación quedaba suspendido como consecuencia del confinamiento domiciliario, por lo que tal medida únicamente podía adoptarse en el marco del estado de excepción. La referida sentencia revocó la prohibición administrativa de celebración de una manifestación al considerar que la situación sanitaria alegada por la Delegación del Gobierno no era razón suficiente para prohibir la celebración de la misma.

${ }_{17}$ Como es sabido, el artículo 11 de la LO 4/1981 establece entre las posibles medidas a adoptar bajo el estado de alarma (apartado a.) el "limitar la circulación o permanencia de personas o vehículos en horas y lugares determinados, o condicionarlas al cumplimiento de ciertos requisitos".

${ }^{18}$ La identificación entre suspensión y afección del contenido esencial del derecho, en relación con los estados excepcionales, ya en CRUZ VILLALÓN, P., (Estados excepcionales y suspensión de garantías, op. cit. p. 76). De este modo, no puede hablarse de limitación que afecte al contenido esencial de un derecho, pues en ese caso siempre nos hallaríamos ante una suspensión del mismo.

${ }^{19}$ Entre otras, SSTC 11/1981, 77/1985, 37/1987 y 112/2006.

${ }^{20}$ Por otro lado, la argumentación que ha señalado que en el caso de la declaración del estado de alarma por el RD 463/2020 no cabe hablar propiamente de suspensión, pues la garantía ordinaria de los derechos afectados (incluido el de libre circulación) ha pervivido, no puede compartirse, ya que dichas garantías subsisten en cualquiera de los estados excepcionales (no sólo en el de alarma), como la propia Constitución (art. 116.6 CE, al disponer que la declaración de los mismos no modificará el principio de responsabilidad del Gobierno y sus
} 
Por el contrario, entre aquellos que han defendido la aplicación del estado de alarma $^{21}$ se ha señalado que la pandemia no encaja como presupuesto de hecho del estado de excepción, que estaría diseñado únicamente para los supuestos de graves alteraciones del orden público. En este sentido, sin perjuicio de lo que después se dirá, no cabe compartir tal argumento, ya que el art. 13 de la LO parte de una consideración del orden público alejada de la propia de épocas pasadas que identificaba tal concepto con la tranquilidad pública o la seguridad ciudadana. Así, como ha tenido ocasión de señalar la doctrina, y, sobre todo, el Tribunal Constitucional (entre otras, STC 19/1985), el orden público a garantizar se debe identificar con aquel estado que permite el ejercicio de los derechos y libertades públicas, siendo por tanto un concepto más amplio que el pretérito o tradicional. De hecho, el propio legislador orgánico así lo presupone (en fecha tan temprana como 1981) al enumerar entre los posibles presupuestos del estado de excepción aquella alteración grave de la normalidad que impida el ejercicio de los derechos y libertades. De este modo, la misma pandemia, y no sólo las medidas administrativas que prácticamente exigía, suponía por sí misma tal alteración grave en el ejercicio de derecho y libertades. La conclusión apuntada se refuerza, además, si se tiene en cuenta que el artículo 13.1 de la LO 4/1981 enumera entre los ejemplos de situaciones que posibilitan la declaración del estado de excepción la alteración grave en el libre ejercicio de los derechos y libertades de los ciudadanos, en el normal funcionamiento de los poderes públicos así como de los propios servicios esenciales para la comunidad, consecuencias que sin

agentes) y la LO 4/1981 establecen (art. 3.1 LO 4/1981, que establece la impugnabilidad en vía jurisdiccional de los actos y disposiciones de la Administración Pública adoptados durante la vigencia de los estados excepcionales). Por lo demás, la aceptación de una tesis como la señalada, que considera que en los estados de excepción y sitio desaparecen las garantías ordinarias de los derechos y libertades suspendidos, no deja de ser problemática por cuanto supone de aceptación de un poder de excepción (en los estados de excepción y sitio) constitutione o legibus solutus, el cual no puede ser contemplado sino con cierto estremecimiento. La vigencia en todo caso, y su exigencia como parámetro de validez de las medidas adoptadas, del principio de proporcionalidad impide hablar de supresión del derecho 0 de sus garantías. Véase REQUEJO RODRÍGUEZ, P., (“¿Suspensión o supresión de los derechos fundamentales?". Revista de Derecho Político, núm. 51, 2001, pp. 105-137), quien recuerda que "la suspensión de derechos no es equiparable a su supresión transitoria".

${ }^{21}$ Así, entre otros, cabe citar a ÁLVAREZ GARCíA, V., (Coronavirus y derecho XLII: las respuestas jurídicas iniciales de la Unión Europea frente a la epidemia de coronavirus. Foro de Investigación en Ciencias Jurídicas y Sociales, 2020), CRUZ VILLALÓN, P., ("La Constitución bajo el estado de alarma. El País, 17/4/2020), DE LA QUADRA SALCEDO, T., ("Límite y restricción, no suspensión". El País, 8/4/2020), GARRIDO LÓPEZ, C., ("La naturaleza bifronte del estado de alarma y el dilema limitación-suspensión de derechos". Teoría y Realidad Constitucional, núm. 46, UNED, 2020, pp. 371-402) y TAJADURA TEJADA, J., ("Derecho de crisis y Constitución", El País, 20/3/2020). 
duda también aparecían ínsitas en la propia situación epidemiológica que atravesaba España en los idus de marzo ${ }^{22}$.

El mismo legislador orgánico partía ya de la consideración de que una situación fáctica que se insertara a priori dentro de los supuestos clásicos del estado de alarma, lo que en la doctrina británica tradicional se conocían como "actos o hechos de Dios", y entre los que se encuentran las enfermedades infecciosas o contagiosas, podía lugar, por la gravedad de su incidencia, a una situación que desembocara en la propia de un estado de excepción. Bien es verdad que el legislador orgánico, de forma un tanto sorprendente, contempló únicamente (art. 28) la situación inversa, al señalar que en el marco del estado de excepción podían adoptarse, si la situación así lo requería, las medidas propias del estado de alarma cuando se dieran además los presupuestos de este último ${ }^{23}$. Y decimos que un tanto sorprendentemente pues el camino lógico y ordinario en la "extraordinariedad" es el inverso, como atestiguara lo sucedido el pasado mes de marzo, esto es, que una situación en principio propia del estado de alarma desemboque por su incidencia (múltiple debido a su gravedad) en una alteración sustancial de la convivencia.

Frente a lo acabado de señalar, se ha argumentado que la LO 4/1981 huyó de la conocida como concepción gradualista de la excepción, de manera tal que los diferentes estados excepcionales no vendrían dados por la intensidad de la crisis sino por tener unos presupuestos fácticos o habilitadores de naturaleza 0 sustancia cualitativamente (y no cuantitativamente) distinta. Así lo ilustraría la modificación operada en la Ponencia del Congreso de los Diputados durante la tramitación del proyecto de la Ley Orgánica, por la que se suprimía el encabezamiento original del hoy artículo 4 en el que se señalaba como primer presupuesto posible del estado de alarma la alteración del orden o de la seguridad ciudadana, cuando su restablecimiento no se pudiera conseguir por medio de las potestades ordinarias de la autoridad gubernativa (de tal manera que, cuando la alteración fuera de una gravedad tal que no pudiera atajarse por

22 Por lo demás, una concepción similar a la aquí defendida sería la acogida por el constituyente portugués, quien en el artículo 19 de la Norma Fundamental lusa establece la posibilidad de que un estado de emergencia desemboque en un estado de excepción cuando las condiciones requeridas para el primero sean más graves, incluyéndose en ambos como presupuesto habilitante el "desastre público" (además, entre otros, de la alteración del orden constitucional).

${ }^{23}$ El art. 28 de la LO 4/1981 dispone que "cuando la alteración del orden público haya dado lugar a alguna de las circunstancias especificadas en el artículo 4ํㅜ o coincida con ellas, el Gobierno podrá adoptar además de las medidas propias del estado de excepción, las previstas para el estado de alarma en la presente ley". 
los medios contemplados para el estado de alarma, procedería la declaración del estado de excepción). Con todo, ha de tenerse en cuenta que si se leen con detenimiento los diarios de sesiones se comprueba que el fin de la modificación señalada, así como de la enmienda que en relación con el artículo 4 fue finalmente aceptada, era el impedir que una huelga o conflicto colectivo que provocase una situación de desabastecimiento o paralización de servicios pudiera "reprimirse" mediante el estado de alarma, ese era su objetivo y no otro. Por otra parte, de aceptar la tesis señalada no se salvaría la contradicción que con respecto a la misma supone lo establecido en el artículo 28, ya referido, artículo que innegablemente articula un puente entre el estado de alarma y el de excepción cuando se den los presupuestos para ello. En el caso analizado tales presupuestos, como se ha indicado, concurrían con creces. La pandemia no suponía solo una crisis sanitaria sino una crisis de convivencia, de modelo de vida, de relaciones intersubjetivas, que iba mucho más allá del presupuesto fáctico típico del estado de alarma, desbordando ampliamente lo previsto constitucional y legalmente en relación con el mismo.

En el fondo, debe admitirse que la situación producida por la covid-19 en el mes de marzo de 2020 distaba de haber sido vislumbrada (y, por tanto, contemplada), siquiera un supuesto parecido, por los autores del texto constitucional y por aquellos que aprobaron la Ley Orgánica de desarrollo del artículo 116 del mismo. Ciertamente, lo imposible se hizo realidad. Pero aun admitiendo lo anterior, la conclusión no puede ser distinta. Así, tendríamos por una parte un presupuesto de hecho propio del estado de alarma (y que según determinado sector doctrinal solo podría justificar el mismo) y unas medidas a adoptar (necesariamente, habría que añadir) que serían las propias del estado de excepción (pues desbordarían ampliamente las previstas para el estado de alarma). Habrían concurrido, pues, un supuesto de hecho de alarma y unas consecuencias o medidas propias del estado de excepción. Tal discordancia (o contradicción, si se quiere) sólo cabría ser resuelta poniendo el acento en el segundo término del binomio, pues la opción inversa no tendría sentido, aparte de no ser admisible constitucionalmente ${ }^{24}$. Podría decirse así, que puestos a

\footnotetext{
${ }^{24}$ Se ha llegado a sostener en defensa de la decantación por el estado de alarma frente al de excepción en la crisis del covid-19 que era preferible el primero dado que en el segundo se contemplan, además de la suspensión de la libertad de circulación, medidas muy drásticas que podrían afectar muy gravemente a otros derechos fundamentales. Tal argumentación no puede por menos que rechazarse a limine. Las otras medidas contempladas como posibles en un estado de excepción por los artículos 16 y siguientes de la LO 4/1981 son eso, posibles, y por tanto, su adopción habría de concretarse entre las propuestas por el Gobierno y ser autorizadas por el Congreso de los Diputados. Así, la declaración del estado de excepción no
} 
elegir, habría que decantarse por las medidas propias del estado de excepción y, por la tanto, por la declaración de dicho estado (por más que el mismo, de admitir la tesis señalada, fuera incongruente), siendo tal opción preferible a una declaración de alarma con las medidas propias de aquel, por claramente insuficientes ante la gravedad de la situación, o con medidas propias del estado de excepción, por lo que supone en este caso de vulneración flagrante y directa de lo establecido por la Constitución en su artículo 55.1 y por las mayores garantías que encierra el segundo con respecto al primero (a las que posteriormente se aludirá).

Sin embargo, la última opción de las acabadas de señalar fue la finalmente elegida por el ejecutivo y posteriormente por la mayoría parlamentaria en la Cámara Baja que con las autorizaciones de las prórrogas pertinentes "validó" políticamente (que no jurídicamente) lo señalado. Estéril, además de inviable por el momento (habrá que esperar a algunas memorias por escribir en el futuro), resulta indagar sobre las razones que estuvieron detrás de la decisión adoptada. Desde el punto de vista jurídico, la exposición de motivos del decreto resulta como mínimo poco convincente, a lo que cabe añadir que el hecho de que no se solicitara dictamen del Consejo de Estado (habiendo sido claramente procedente) añade más incertidumbre a la cuestión. Se ha llegado a indicar como refuerzo de la pertinencia de la declaración del estado de alarma, con preferencia al de excepción, el argumento de la necesaria rapidez o urgencia en la intervención del ejecutivo, de tal manera que el acudir a este último hubiera retrasado en exceso la inmediatez necesaria en la respuesta, ya que se hubiera precisado la convocatoria del Congreso de los Diputados, con la consiguiente pérdida de tiempo. Sin embargo, no cabe admitir tal argumento por diversas razones. En primer lugar, por cuanto que la convocatoria del Congreso de los Diputados y la celebración de la correspondiente sesión puede realizarse en cuestión de horas. De otro lado, tanto en la declaración del estado de alarma correspondiente al mes de marzo, como más si cabe aún en la realizada en el mes de octubre, se trataba de una decisión que el Gobierno estuvo sopesando durante días (hasta el punto de que algunas Comunidades Autónomas habían adoptado medidas restrictivas desde hacía días), tal y como

supone por sí misma la inclusión in totum de todas las medidas contempladas en la Ley Orgánica, sino solo aquellas solicitadas por el Gobierno y autorizadas por la Cámara Baja. De haberse recurrido a la vía del estado de excepción se hubiera limitado en su caso a la suspensión del derecho de circulación. Dicho sea con todos los respetos, una argumentación semejante a la señalada llevaría a prohibir los cuchillos de cocina por su posible empleo como arma de un homicidio. 
se hicieron eco los medios de comunicación, no pudiendo hablarse por tanto de un hecho de aparición súbita que exigía una respuesta instantánea por parte de los poderes públicos. Por otra parte, el argumento esgrimido conduce a un evidente contrasentido, ya que en supuestos que pueden ser más graves que los determinantes del estado de alarma, como son los habilitantes de los estados de excepción y sitio, es obligado convocar al Congreso de los Diputados (para autorizar o declarar) aun cuando la intervención de este necesariamente no sea cien por cien inmediata (siempre llegará con cierto retraso, por razones obvias), por lo que de aceptarse el argumento señalado nunca se declararía el estado de excepción o el de sitio $^{25}$.

En la opción final por el estado de alarma quizás pesara en el ánimo del ejecutivo (confesado incluso desde alguna tribuna por algunos de los defensores de la vía escogida) el deseo de huir de una denominación que en el imaginario colectivo patrio podía despertar recuerdos de otra triste realidad felizmente superada. Prurito, por lo demás, excesivo (pues las resonancias sólo reverberarían en la población de más edad) y a todas luces inadmisible si ello suponía una directa vulneración del texto constitucional democrático de 1978, que acogió la denominación, por otra parte, clásica, de estado de excepción. Si bien la huida nominal puede entenderse, aunque no compartirse, no cabe concluir de idéntica forma si la misma conlleva una huida jurídica.

El caso es que, en definitiva, "la rosa no fue llamada por su nombre". Y ello, además de lo señalado, explicaría buena parte de las contradicciones, lagunas $y$, en algunos casos, desbordamientos del marco constitucional y legal que se detectan en las medidas adoptadas para hacer frente a la pandemia, y no sólo durante la conocida como primera oleada sino posteriormente y aun en los momentos en que se escriben estas líneas. Muchos de los vaivenes producidos, de los aludes de medidas y contramedidas (reformas legislativas algo apresuradas incluidas), amén de rectificaciones, e incluso alguna que otra

\footnotetext{
${ }^{25}$ A este respecto resulta de interés recordar que la Ley Fundamental de Bonn, en su regulación del estado de defensa, parte de la consideración de que la declaración por el Bundestag podrá no ser inmediata (por imposibilidad fáctica de reunir al Bundestag, o a la comisión de conciliación en su caso, de forma simultánea a la "aparición" de la emergencia), permitiendo al ejecutivo que entretanto pueda adoptar las medidas estrictamente necesarias que exija la situación. En relación con lo señalado, y volviendo al caso español, el que la obligada intervención parlamentaria no pueda producirse sin solución de continuidad con la decisión del ejecutivo de instar una eventual declaración del estado de excepción, no puede justificar en ningún caso el acudir al estado de alarma para adoptar medidas propias del primero, ignorando además la obligatoriedad de la intervención "inicial" del órgano representativo del titular de la soberanía.
} 
pugna política, posiblemente se hubieran evitado si desde el primer momento se hubieran "llamado a las cosas por su nombre" y se hubiera sido consecuente con la situación real.

El estado de alarma suponía, frente al de excepción, que el Gobierno podía adoptar la decisión inicial en un primer momento (ya que, como es sabido, la declaración del de excepción requiere de la autorización del Congreso de los Diputados), pero, una vez adoptado, las implicaciones en las relaciones entre poderes u órganos constitucionales son idénticas (si bien no del todo, como se verá) en uno caso y otro caso, ya que la prórroga del estado de alarma también ha de ser autorizada por la Cámara Baja. La principal diferencia reside en la regulación de los plazos de las prórrogas, en cuanto que para el estado de alarma no se limita el número de prórrogas posibles (ni se especifica su duración), mientras que en el caso del estado de excepción la Constitución y la Ley Orgánica sólo hace referencia a una única prórroga. Con independencia de lo que se señaló con anterioridad y de lo que posteriormente se apuntará en relación con los plazos, lo cierto es que desde el punto de vista de relaciones entre poderes no existe una diferencia sustancial entre los dos estados excepcionales comentados, lo que hace menos justificable, 0 al menos comprensible, la postura adoptada.

Por lo que respecta al conocido como proceso de desescalada, hay que señalar que en este la conclusión en relación con la suspensión (general) de derechos y la procedencia del estado de excepción en lugar del de alarma, ha de ser matizada, ya que en las fases más avanzadas de aquel la regla general fue la libertad de circulación con salvedades. Lo mismo cabría concluir en relación con determinadas restricciones que quedarían subsistentes en el período denominado como "nueva normalidad", en especial, por lo que se refiere a la obligatoriedad del uso de mascarillas en determinados espacios o la llamada distancia de seguridad.

Sin embargo, la aparición durante la fase central del verano de nuevos brotes epidemiológicos de cierta intensidad en determinados ámbitos geográficos (caso destacado de diversas zonas de Aragón) dio lugar a la adopción por diversas Comunidades Autónomas de los llamados "cierres perimetrales", esto es la prohibición de entrada y salida de los municipios afectados. Como es sabido, dichas administraciones recurrieron a la vía establecida por el entonces artículo 8.6 de la Ley de Jurisdicción contencioso-administrativa, cuya 
aplicación era muy cuestionable, toda vez que el mismo contemplaba la autorización judicial para la adopción de medidas que supusieran limitación de la libertad por motivos sanitarios, medida claramente pensada única y exclusivamente para supuestos en los que la concreción de las personas afectadas apareciera delimitada de manera precisa e individualizada ${ }^{26}$. En dichos casos se trataba de confinamientos que afectaban de manera general a categorías generales personas, esto es, los residentes de determinados municipios, lo que difícilmente podía conciliarse con lo establecido en la legislación ordinaria, tal y como se ha señalado. Por lo demás, este fue, entre otros, el motivo por el que determinados órganos jurisdiccionales (no todos) negaron la consiguiente autorización en algunos casos, creándose una situación de disparidad interpretativa que causó evidente desconcierto en la opinión pública.

Precisamente, fue la disparidad aludida en la interpretación jurisprudencial la que motivó la reforma legislativa express de la Ley de Jurisdicción Contencioso-Administrativa, cuyo nuevo apartado 8 del artículo 10 atribuyó la competencia para otorgar la referida autorización judicial a las Salas de lo contencioso-administrativo de los Tribunales Superiores de Justicia de las Comunidades Autónomas en los casos en los que las medidas restrictivas de la libertad fueran adoptadas respecto a una generalidad indeterminada de personas $^{27}$. La constitucionalidad del precepto resulta más que cuestionable, ya que la suspensión general de un derecho o libertad sólo puede producirse en el marco del estado de excepción o de sitio, por mor de lo establecido en la propia Constitución.

Por otra parte, no dejaba de resultar como mínimo llamativo que se supeditara la entrada en vigor de una disposición de alcance general a la previa ratificación o autorización judicial. Nos hallábamos ante una disposición general y no un acto administrativo (por más que en ocasiones la distinción entre unas y otros aparezca revestida de cierta complejidad o dificultad), ya que se trataba

\footnotetext{
${ }^{26}$ Así, no en vano dicha previsión se contempla de forma subsiguiente a la contenida en dicho artículo (párrafo primero del art. 8.6 LJCA) en relación con la competencia de los juzgados de lo contencioso-administrativo para la autorización de entrada en domicilio cuyo acceso requiriese el consentimiento de su titular para la ejecución forzosa de actos administrativos.

27 Dicho apartado, introducido por la Ley $3 / 2020$, de 18 de septiembre, establece que "conocerán de la autorización o ratificación judicial de las medidas adoptadas con arreglo a la legislación sanitaria que las autoridades sanitarias de ámbito distinto al estatal consideren urgentes y necesarias para la salud pública e impliquen la limitación o restricción de derechos fundamentales cuando sus destinatarios no estén identificados individualmente".
} 
de medidas que no se agotaban con su cumplimiento, sino que tenían vocación de permanencia en el tiempo durante el lapso de duración de la misma (criterio principal en la distinción entre disposición y acto de alcance general) ${ }^{28}$. Así, pues, se articuló un caso único en nuestro ordenamiento, ya que se trataba de disposiciones normativas cuya eficacia o entrada en vigor se supeditaba a una previa autorización por parte de un poder del Estado, el judicial, frente a la regla general que determina que este interviene de forma reactiva, esto es, ex post facto, una vez que cobra vigencia la norma (y normalmente con ocasión de la aplicación de los actos administrativos dictados en ejecución de la misma). De este modo, resultaba sorprendente que el poder del Estado llamado a responder ante una situación justificativa de un estado excepcional, esto es, el Gobierno de la Nación, no actuara, y, en cambio interviniera de una forma completamente extraña a su operatividad natural el poder judicial ${ }^{29}$.

Por todo ello, no cabe sino concluir que también para los denominados casos de confinamientos perimetrales, por muy localizados que fueran, hubiera sido necesaria la declaración del estado excepcional pertinente. Con respecto a esto último, podrían plantearse más dudas en relación a si la única vía pertinente hubiera sido el estado de excepción, ya que en los casos de núcleos poblacionales muy acotados la prohibición de salir o entrar pudiera ser valorada como una restricción y no una suspensión general del derecho. Con todo, siendo más garantista la vía del estado de excepción, el principio del favor libertatis haría más aconsejable en tales casos la declaración del mismo con preferencia al del estado de alarma.

Un paso cualitativamente distinto es el que se dio, se ha dado, mediante la adopción de medidas que inciden de modo directo en las posibilidades de relación intersubjetivas. Nos referimos, claro es, a aquellas medidas que prohíben, o si se quieren limitan, la presencia en la calle, y como más tarde se estableció, también en domicilios, a un determinado número de personas, normalmente integrantes de un mismo núcleo de convivencia. Las primeras de estas medidas se adoptaron en los comienzos de la denominada segunda ola, no estando vigente ningún estado excepcional. Así, fue la Comunidad

\footnotetext{
${ }^{28}$ Véase, ENRÍQUEZ MALAVÉ, G., "Naturaleza jurídica de las medidas sanitarias adoptadas frente al COVID.19: ¿Actos administrativos o disposiciones judiciales?”. Diario La Ley, no 9740, 20/20/2020.

${ }^{29}$ En buena parte debido a los motivos expuestos, la sección 1 a de la sala de lo ContenciosoAdministrativo del Tribunal Superior de Justicia de Aragón, mediante auto de 3 de diciembre de 2020, acordó plantear la cuestión de inconstitucionalidad en relación con el art. 10.8 de la LJCA, pendiente de resolución en el momento en que se escriben las presentes líneas.
} 
Autónoma de Galicia la que, ante la evolución de la pandemia en la ciudad de Ourense, prohibió en dicha ciudad la presencia en las vías y espacios de uso público (locales de restauración incluidos) así como en espacios privados de grupos mayores de diez miembros ${ }^{30}$, cifra que más adelante sería rebajada a cinco, añadiéndose que tales grupos solo podían ser de convivientes en un mismo domicilio ${ }^{31}$. Posteriormente, la medida sería replicada con mayores o menores variaciones por otras Comunidades Autónomas. Más tarde, el Real Decreto 926/2020, de 25 de octubre, por el que se declara el estado de alarma en todo el territorio nacional, así como aquel por el que se articula su prórroga con una extensión de seis meses, estableció la referida prohibición en lo que respecta a los domicilios, señalándose que en los mismos no podrían coincidir más de seis personas ${ }^{32}$, sin perjuicio de que las Comunidades Autónomas puedan modular tal medida.

Ha de destacarse en primer término que la adopción inicial por las Comunidades Autónomas de medidas como las referidas desborda ampliamente su margen competencial. Al tratarse de una medida de carácter generalizado, la misma excede de aquellas que le permite tomar la legislación sanitaria. Por otra parte, las medidas descritas, en especial, la limitación de prohibición de presencia en domicilios de personas que no vivan en el mismo suponen una intensísima afección del propio derecho a la libertad personal, hasta el punto de que ciertamente cabría hablar también aquí de una suspensión de derechos y libertades ${ }^{33}$. De este modo, la adopción de una medida tal no solo excede con creces las potestades de las Comunidades Autónomas, incluidas sus competencias de lucha contra una epidemia, sino que incluso tendría difícil encaje en el ámbito propio del estado de alarma. De hecho, el propio control del cumplimiento de la medida nos estaría indicando ya que la misma sólo podría adoptarse en el marco de un estado de excepción (o

\footnotetext{
${ }^{30}$ Orden de la Consellería de Sanidad de la Xunta de Galicia de 2 de septiembre de 2020.

${ }^{31}$ Orden de la Consellería de Sanidad de la Xunta de Galicia de 2 de octubre de 2020.

${ }^{32}$ Con la excepción, claro es, de que el núcleo de convivencia englobara a un mayor número.

${ }^{33}$ Consideración que cabe realizar aún más si cabe en relación con la medida adoptada en el ámbito territorial del Municipio de Ourense, ya referida, y posteriormente extendida a otros municipios de Galicia (Decreto 178/2020, de 30 de octubre, del Presidente de la Xunta de Galicia), por la que se establecía que la presencia de una pluralidad de personas tanto en espacios públicos como privados únicamente era permitida en el caso de grupos de convivientes. La libertad de relación del individuo con otras personas aparecía, pues, muy intensamente afectada. Piénsese, por ejemplo, que la Orden referida impedía coincidir en espacios públicos o privados a personas que mantuviesen una relación afectiva, pero no convivieran (afectando aún con más rigor a las personas que vivieran solas, quienes ni siquiera podían relacionarse con otras en espacios físicos, más allá del ámbito laboral).
} 
de sitio), dado que la comprobación de su eventual incumplimiento sólo podría lograrse mediante la entrada en domicilios por parte de los agentes de la autoridad, algo vedado en el estado de alarma (más allá de los casos ordinarios, esto es, con autorización judicial en el marco de una investigación penal, o sin ella cuando se estuviera cometiendo un delito flagrante, lo que no sería el caso).

En definitiva, que medidas como las acabadas de describir hayan sido aceptadas con gran civismo por la práctica totalidad de la población afectada (todo el país) no puede llevar a banalizar la gravedad (si se permite el término) de las mismas, ya que afectan a una esfera vital de la máxima relevancia para cada persona, esto es, su derecho a relacionarse con sus semejantes.

Por otra parte, por lo que respecta al conocido como toque de queda, establecido en el decreto 926/2020 por el que se declara el estado de alarma, por el que, en este aspecto, se prohíbe la circulación por la vía pública entre la medianoche y las seis de la mañana, es probablemente la medida que, aun con cierto forzamiento hermenéutico, podría subsumirse en el ámbito de aquellas permitidas o previstas bajo la vigencia del estado de alarma por la LO 4/81. Con todo, su generalidad en cuanto a destinatarios, lapso y ámbito (todas las vías públicas) hace que dicha medida se encuentre en la frontera con la suspensión del derecho o libertad (en este caso la del artículo $19 \mathrm{CE}$ ) del artículo 55.1 de la Constitución (de hecho, históricamente el toque de queda se ha identificado con el estado de excepción).

Llegados a este punto, corresponde abordar un aspecto que no hace sino corroborar que lo procedente en la coyuntura vivida, y en concordancia con las medidas adoptadas, no era sino la declaración del estado de excepción. Nos referimos a la cuestión del plazo de la prórroga del estado de alarma. Como es sabido, la Constitución y la LO 4/1981 ${ }^{34}$ establecen que la declaración inicial del estado de alarma será por quince días, señalando que podrá ser prorrogado, si bien no se concreta la duración de la prórroga (ni su posible número). En el caso precedente de la declaración del estado de alarma concerniente a la conocida como crisis de los controladores aéreos, el Gobierno, con la pertinente autorización del Congreso de los Diputados, acordó prorrogar la declaración inicial del estado de alarma por un período superior a

${ }^{34}$ Art. 116.2 CE y 6.2 LO 4/1981. 
quince días ${ }^{35}$, entendiendo que la Constitución ni la Ley Orgánica establecían plazo alguno. Con ocasión de la primera oleada del coronavirus el ejecutivo optó por solicitar las primeras prórrogas del estado de alarma por una duración de quince días. Sin embargo, en un momento dado (finales de mayo) se aludió a la posibilidad de que las sucesivas lo fueran por un período superior, lo que dio lugar a un intenso debate acerca de si era o no procedente una prórroga que excediera del plazo máximo fijado para la declaración inicial. Finalmente, se optó por seguir prorrogando por plazos de quince días.

No obstante el precedente comentado, en el contexto de la segunda ola de la pandemia, el Gobierno solicitó una prórroga del estado de alarma por una duración de seis meses, siendo la misma autorizada por la Cámara baja. Así se hizo por Real Decreto 956/2020, de 3 de noviembre. Dicha prórroga, que ha sobrepasado con creces los precedentes señalados, se antoja a todas luces excesiva. Desde el punto de vista jurídico-constitucional, resulta cuando menos cuestionable que un estado de alarma se prorrogue por dicho plazo, y no sólo por las razones aludidas, sino también por cuanto que los propios supuestos fácticos de tal estado previstos en la Ley Orgánica 4/1981 casan mal con dicha duración. Lo señalado no hace sino confirmar que materialmente nos hallamos, tanto por los presupuestos fácticos como sobre todo por el tipo de medidas que exigen los mismos, ante un supuesto que se corresponde más bien con el diseño constitucional y legislativo (orgánico) del estado de excepción. Como se recordará, la duración del mismo es de treinta días, prorrogables por otros treinta, no señalando la Constitución ni la Ley Orgánica nada respecto a la posibilidad de ulteriores prórrogas. Con todo, como ha indicado la mejor doctrina en la materia, en los supuestos en que se prolongara la necesidad de la vigencia del estado de excepción cabría proceder a una nueva declaración de dicho estado ${ }^{36}$. De este modo, dada la gravedad de las medidas adoptadas (y de la situación que las determina), es sorprendente, si no manifiestamente rechazable, que el órgano representativo del titular de la soberanía, no se pronuncie sobre las mismas y su vigencia en un lapso de seis meses (por mucho que subsista el control ordinario del Gobierno). En el marco del estado de excepción, el pronunciamiento parlamentario, en este caso en forma de autorización, se produciría al menos cada treinta días, lo cual resulta mucho más acorde con la situación vivida y con la intensidad de la afectación que en

\footnotetext{
${ }^{35}$ El decreto de prórroga (RD 1717/2010) estableció una duración para la misma de 29 días, desde el 18 de diciembre de 2010 hasta las 24 horas del 15 de enero de 2011.

${ }^{36}$ CRUZ VILLALÓN, P., Estados excepcionales..., op. cit., p. 91.
} 
la esfera de los derechos y libertades ciudadanas suponen las medidas adoptadas. Así, pues, cabría concluir al respecto que todo lo apuntado no hace sino corroborar que nos hallamos en el "estado equivocado" (o, mejor dicho, que se ha designado a un estado con una denominación que no le corresponde).

Además de lo indicado hasta el momento, referido principalmente a la suspensión-limitación de derechos fundamentales, se han de señalar otros aspectos del iter seguido susceptibles de crítica.

A este respecto, cabe analizar en primer término el papel de las Comunidades Autónomas a lo largo de este proceso, y, en concreto, su adecuación o no al marco constitucional y normativo existente. Como es sabido, fueron las Comunidades Autónomas las primeras en adoptar medidas en la segunda semana de marzo ante el avance del entonces desconocido virus. Así, diversas de ellas aprobaron medidas en relación con el cierre de centros educativos, en primer término, y posteriormente, el de locales de restauración (casos destacados de Madrid, Galicia y País Vasco), acordando incluso alguna el cierre perimetral de determinados municipios. Una vez que se declaró por el Gobierno de la Nación el estado de alarma, este asumió todas las competencias que el mismo le habilita, y se designó como autoridad delegada a los Ministros de Sanidad, Defensa, Interior y de Transporte, Movilidad y Agenda Urbana. Ya durante el denominado proceso de "desescalada", los diversos decretos de prórroga del estado de alarma procedieron a establecer el que entonces fuera denominado como régimen de "cogobernanza", en el que, desbordándose lo previsto en la LO 4/1981, asumieron la condición fáctica de autoridad delegada el Ministro de Sanidad y los Presidentes de las Comunidades Autónomas. Políticamente se justificó tal medida aludiendo a que las Comunidades Autónomas son las principales Administraciones competentes en los servicios más afectados por la pandemia, singularmente el sanitario (amén de otro como el educativo).

El siguiente jalón en el proceso descrito fue la adopción de medidas por diversas Comunidades Autónomas durante el conocido como período de "nueva normalidad" (principalmente verano de 2020), medidas a las que ya nos hemos referido en sentido crítico, toda vez que muchas de ellas únicamente pueden adoptarse en el marco de la declaración de un estado de excepcional (como corroboración de lo señalado, cabe recordar que desde muchas 
Comunidades Autónomas se señaló que se estaban tomando medidas ante la inacción del Gobierno central). Precisamente, el fenómeno señalado dio lugar a una gran heterogeneidad en las respuestas parciales que desde las Comunidades Autónomas se dieron a la situación, originando episodios de descoordinación evidente.

El Real Decreto 926/2020, de 25 de octubre, por el que se declara el estado de alarma ante la segunda oleada en la propagación del covid-19 dio un paso más en relación con los decretos de desescalada al designar como autoridad delegada en cada Comunidad Autónoma al respectivo Presidente de la misma. Ello suponía una contradicción con lo establecido en la LO 4/1981, ya que en esta se señala que sólo cabrá designar como autoridad delegada a un Presidente autonómico cuando el estado de alarma se refiera 0 afecte exclusivamente al territorio o parte de una Comunidad Autónoma (art. 7$)^{37}$. Por lo demás, el decreto establece una descripción de las medidas que pueden adaptarse por las Comunidades Autónomas, con ciertos requisitos, imponiendo obligatoriamente otras (que a su vez las Comunidades Autónomas podrán modular).

La situación descrita no puede por menos que valorarse negativamente. Además del extravase evidente de lo establecido en la LO 4/1981 ha de indicarse que la articulación jurídica del régimen de "cogobernanza", si bien imaginativa en sentido positivo en algunos aspectos, ofrece muchas lagunas y contradicciones. Como ya se ha indicado, la respuesta parcial y diferente (en muchos aspectos de manera incomprensible para los ciudadanos) en diversos territorios del Estado español ha generado evidente confusión y desconcierto, cuando no ineficacia ante un virus que, resulta obvio, no entiende de "fronteras" administrativas de cara a su propagación. Si las Comunidades Autónomas ostentan las competencias ordinarias de sanidad, ejercicio realizado con gran eficacia por lo demás, en el supuesto de una innegable "extraordinariedad" se encuentra más que justificado que exista una respuesta lo más homogénea posible en el conjunto del territorio nacional.

Por otra parte, ha de hacerse mención como aspecto igualmente cuestionable al de la proliferación de preceptos y conceptos indeterminados y de remisiones

${ }^{37}$ El artículo 7 de la LO 4/1981 no deja duda al respecto al disponer que "a los efectos del estado de alarma la Autoridad competente será el Gobierno, o por delegación de este, el Presidente de la Comunidad Autónoma cuando la declaración afecte exclusivamente a todo o parte del territorio de una Comunidad". 
en blanco contenidos en los decretos por los que se ha decretado el estado de alarma así como sus prórrogas. Debe reconocerse que la absoluta novedad de la situación confrontada podía justificar en algunos casos que no se pudiera cerrar un elenco de respuestas tasadas ante las diversas coyunturas, pero ello no obsta para que se concluya la inadmisibilidad de remisiones excesivamente abiertas e indeterminadas realizadas por los decretos. Estos ya preveían la propia mutabilidad de las medidas, dejando horquillas en algunos casos, pero en determinados supuestos las modificaciones "permitidas" suponían y suponen una auténtica novación del propio decreto del estado de alarma, y, lo que es especialmente relevante a los efectos jurídico-constitucionales, de los términos en los que el Congreso de los Diputados otorgara su autorización a las concretas prórrogas solicitadas por el Gobierno.

Lo señalado no se refería únicamente a las medidas a adoptar para responder a la pandemia, sino que la indeterminación también "abarcaba" a los presupuestos de hecho que permitían la adopción de las mismas. Así sucedió en la denominada "desescalada", en la que se establecieron sucesivas fases que implicaban diferentes medidas graduadas en su intensidad en función de la situación en que se encontrara el territorio afectado, sin que en los propios decretos de prórroga del estado de alarma se explicitara el régimen jurídico anudado a las diferentes fases y sin que se establecieran en los mismos los criterios o parámetros que determinaran la inserción en una u otra fase, remitiéndose para ambos extremos al denominado "Plan de Desescalada" aprobado por Acuerdo de Consejo de Ministros $^{38}$, acuerdo que no llegó a ser objeto de publicación en el Boletín Oficial del Estado (sí se "colgó" en la web del ejecutivo $)^{39}$. No hará falta insistir al respecto en que el hecho de hallarnos ante un derecho como el de excepción, que implica una intensa restricción, cuando no suspensión, de derechos y libertades, hace más exigible que en otros casos la vigencia del principio de tipicidad "restrictiva o limitativa", de tal manera que sean absolutamente rechazables remisiones en blanco 0 preceptos indeterminados.

\footnotetext{
${ }^{38}$ Plan para la desescalada de las medidas extraordinarias adoptadas para hacer frente a la pandemia de COVID-19, aprobado por Acuerdo del Consejo de Ministros de 28 de abril de 2020.

${ }^{39}$ Véase GARRIDO MAYOL, V., "Limitaciones y suspensiones de derechos. Muchos puntos controvertidos", en Antes de la próxima pandemia (RECUERDA GIRELA, M. A., coord.). Aranzadi, 2020, p.162.
} 
En conexión con lo anterior, ha de indicarse que ha resultado cuando menos llamativo el menguante papel que las Cortes Generales, y en particular la Cámara Baja, ha jugado con ocasión de la mayor crisis de la historia nacional en medio siglo, que ha conllevado la adopción de medidas desconocidas por su afectación en la esfera de libertades de los ciudadanos. Por más que dichas inmisiones en la libertad individual y colectiva estuviesen más que justificadas, la intensidad de las mismas exigía un mayor protagonismo del órgano representativo del titular de la soberanía. Si bien los estados excepcionales, por su propia idiosincrasia, representan "la hora del ejecutivo", en cuanto único órgano constitucional que puede responder con eficacia ante una situación de extrema urgencia y gravedad, el control por parte del Parlamento ha de estar si cabe más activo que nunca, ante el riesgo cierto de que la mayor concentración de poderes en aquel pudiera desbordar el marco jurídico-constitucional.

La propia declaración del estado de alarma en lugar del de excepción ya anunciaba ese papel capitidisminuido del Congreso de los Diputados, a lo que se unió en un primer momento una drástica cuasiparalización de la actividad parlamentaria, en contraste, por lo demás, con lo que sucedía en otros parlamentos de nuestro entorno. La misma celeridad en la tramitación de las autorizaciones de las prórrogas evidenció con claridad lo señalado. Ciertamente, que la autorización de medidas que, por más que justificadas, iban a afectar a las vidas de millones de seres humanos, sólo mereciera un día (o a veces medio) de debate es un dato que ha de llevar a la reflexión, contrastando, además, con lo sucedido en otros países, en los que las leyes de emergencia o las autorizaciones de estados excepcionales se discutieron a lo largo de varias sesiones (incluidas nocturnas, como sucediera en el Parlamento francés). A lo señalado hay que añadir el sorprendente escaso número de enmiendas presentadas, lo que, si bien puede ser valorado positivamente como expresión de un consenso político ante la gravedad de la situación, no despeja del todo la duda acerca de si más bien responde a esa difuminación del papel del Parlamento de la que la doctrina viene hablando desde hace décadas, y respecto de la cual la crisis vivida no ha supuesto un golpe de timón, sino más bien lo contrario. La autorización parlamentaria de la prórroga del estado de alarma nada menos que por un periodo de seis meses bien puede considerarse como el epítome del proceso descrito. La previsión de la comparecencia del Gobierno cada dos meses en relación con lo señalado es, cuando menos, manifiestamente insuficiente. 


\section{REFORMAS PARA EL FUTURO}

Del análisis de las páginas precedentes cabe concluir que resulta conveniente, cuando no imprescindible, acometer reformas normativas que permitan una más eficaz respuesta, proporcionen una mayor seguridad jurídica, así como resuelvan las lagunas y contradicciones detectables en la legislación vigente en la actualidad.

Con carácter previo, se ha de subrayar que, frente a lo preconizado desde distintas posiciones, la legislación sanitaria ordinaria (para casos extraordinarios) y/o su reforma como vía de respuesta a una crisis sanitarioepidemiológica como la provocada por la covid-19 se antojan insuficientes, cuando no improcedentes. Conocido es que el marco de la misma viene constituido por la Ley General de Sanidad (Ley 14/1986, de 25 de abril), la Ley General de Salud Pública (Ley 33/2011, de 4 de octubre) y, en especial, por la Ley Orgánica de Medidas Especiales Sanitarias (Ley Orgánica 3/1986, de 14 de abril). Por lo que respecta a su configuración actual, resulta claro que la misma no puede erigirse en mecanismo a través del cual luchar contra la pandemia, toda vez que aquella contempla únicamente medidas de carácter singularizado, esto es, para personas o grupos de personas concretos, no pudiendo invocarse como base normativa que ampare medidas de carácter general, que tengan como destinatarios a la globalidad de la población española, como las adoptadas desde hace meses en nuestro país y que aún rigen en el mismo (así, por ejemplo, las leyes citadas y la Ley Orgánica se refieren al control de enfermos o personas sospechosas de estar enfermas ${ }^{40}$ ). En relación con lo apuntado, no es aceptable que, como se ha llegado a sugerir, la cláusula general de habilitación de adopción de cuantas medidas sean necesarias contenida en la LO pudiera servir como justificación para permitir la adopción de medidas que, como las acordadas, suponen una restricción (en muchos casos rayanas en la suspensión) de los derechos y libertades de todos los que se hallen en territorio español. Ni el principio de

\footnotetext{
40 El art. 3 de la LO 3/1986 establece que "con el fin de controlar las enfermedades transmisibles, la autoridad sanitaria, además de realizar las acciones preventivas generales, podrá adoptar las medidas oportunas para el control de los enfermos, de las personas que estén o hayan estado en contacto con los mismos y del medio ambiente inmediato, así como las que se consideren necesarias en caso de riesgo de carácter transmisible".
} 
tipicidad ni el propio espíritu de la LO dan margen para tal interpretación, absolutamente rechazable.

De otra parte, tampoco la vía de una reforma legislativa de la normativa sanitaria que contemplara específicamente un elenco detallado de medidas como las adoptadas en los últimos meses puede ser considerada como la mejor opción. Así, como ya se ha comprobado, pandemias de alta capacidad de propagación y letalidad exigirán una respuesta que suponga la suspensión de determinados derechos y libertades, suspensión que sólo puede adoptarse en el marco de la declaración de un estado de excepción (o sitio), de conformidad con lo establecido en la Constitución. Pero es que, más aún que lo anterior, ha de tenerse presente que la Constitución ha reservado la regulación de una situación excepcional, del tipo que sea, a una Ley Orgánica específica, que no es otra que la Ley Orgánica reguladora de los estados de alarma, excepción y sitio (como sucede con otras remisiones o reservas realizadas por el constituyente, como es el caso de las realizadas a la LOREG o a la LOPJ). Ninguna otra norma podría, por tanto, regular la excepción, sea de modo explícito o implícito, en este último caso disponiendo medidas que, como la suspensión de derechos y libertades, sólo pueden adoptarse en el marco de los estados excepcionales.

En cualquier caso, incluso salvando las objeciones que anteceden, lo cierto es que no se alcanza a comprender la defensa de la suficiencia e idoneidad de la respuesta sanitaria ordinaria, esto es, la proporcionada por la legislación específicamente tal, pues se trataría (admitiendo los postulados de los defensores de tal posición) de llegar al mismo puerto que con el estado de alarma o excepción, siguiendo un camino más largo, y con menores garantías que las proporcionadas por estos últimos. Debe insistirse en que el hecho de que nuestra Constitución (y en desarrollo de la misma la LO 4/1981) prevea específicamente la excepción es una riqueza de nuestro bagaje jurídicoconstitucional, y no precisamente lo contrario como a veces se ha podido dar a entender. Si existe tal riqueza, aprovéchese. Y se señala que nuestros artículos 116 y 55.1 de la Norma Fundamental constituyen un acertado instrumento, por cuanto que los mismos establecen una serie de garantías al máximo nivel normativo que la legislación ordinaria hoy no contiene ni puede seguramente contener. Unas garantías que operan no sólo frente al poder del Estado, el ejecutivo, llamado a gestionar la crisis, sino incluso frente a los otros dos, el judicial y, señaladamente, el legislativo. Cuando se ha querido comparar la 
respuesta española ante la covid-19 con la articulada en otros países como punto de apoyo para la postura aquí glosada, se ha solido olvidar que en la mayoría de casos estos últimos carecían de cualquier previsión constitucional al respecto, frente a lo que ocurre en nuestro ordenamiento. Se trató en el caso español de una opción bien consciente del constituyente, pero precisamente con la voluntad de rodear la excepción de las mayores garantías posibles, y no a la inversa. Por ello, el empeño en querer afrontar situaciones como la vivida a través de la legislación sanitaria ordinaria no es sino una banalización de la excepción, con los riesgos que ello puede comportar. Las medidas adoptadas en los últimos meses en nuestro país, justificadas por otra parte, han afectado de una manera intensísima a las vidas de millones de españoles: a sus relaciones afectivas, a su salud emocional, a sus propios medios de subsistencia..., por ello, a la gravedad en la respuesta ha de corresponderse una garantía máxima en su declaración y aplicación.

Así, pues, si, como se ha de concluir necesariamente, ha de reformarse nuestro ordenamiento para acomodarse a la nueva realidad de la excepción contemporánea puesta de manifiesto con la crisis del covid-19, sin perjuicio de la reforma de la legislación sanitaria, ha de partirse de la obligada modificación del marco jurídico regulador de la excepción, entendida esta en un sentido amplio. Como se indicara con anterioridad, la reciente crisis ha revelado la existencia de lagunas ( $\mathrm{y}$ también contradicciones) en dicho marco que han de ser colmadas normativamente de cara al futuro. En el sentido indicado, podrían señalarse dos posibles vías: una que contemplara exclusivamente la modificación de la Ley Orgánica 4/1981, y otra que conllevase además una reforma constitucional que afectara a los artículos reguladores de la excepción.

Por lo que respecta a la primera de las vías señaladas, existen una serie de cuestiones que concitarían la práctica unanimidad en cuanto a la pertinencia de su regulación-modificación en la LO 4/1981. Así, en primer término, habría de clarificarse en la Ley Orgánica la polémica cuestión del plazo de las prórrogas de los estados de alarma y excepción. De este modo, podría señalarse en la Ley Orgánica que cada prórroga del estado de alarma no pudiera durar más de 15 días, y en lo concerniente al estado de excepción establecer expresamente que el mismo únicamente puede ser prorrogado por una sola vez (el que la LO permitiera un mayor número de prórrogas sería problemático desde el punto de vista constitucional), admitiéndose en el caso de agotamiento de la misma una nueva declaración del estado de excepción. 
Otro aspecto que demanda una reforma es el relativo al control parlamentario, y, más ampliamente, a la intervención del Parlamento en la declaración y seguimiento de los estados excepcionales. Con todo, sin perjuicio de que la LO 4/1981 pudiera reforzar el papel del Parlamento (y no sólo de la Cámara Baja) en el control de la actuación del Gobierno en los estados excepcionales, la sede más idónea para ello son los Reglamentos de las Cámaras. En este sentido, resulta más que conveniente una regulación exhaustiva del control parlamentario en tales supuestos, con previsión de mayores instrumentos para ello, así como mediante la articulación de un mayor número de comparecencias obligadas de los miembros del ejecutivo y unos más amplios plazos de enmiendas y tiempos de intervención relacionados con aquellos.

De otro lado, no cabe duda de que el ensamblaje del derecho de excepción con nuestro actual Estado autonómico es otra cuestión que reclama la reforma de la LO 4/1981. Con todo, el hecho de que las Comunidades Autónomas sean las principales gestoras de las competencias involucradas en una crisis como la vivida no debe hacer olvidar que la excepción, por su propia naturaleza, exige la concentración de competencias y potestades con el fin de conseguir una más rápida y eficaz respuesta. En relación con ello, crisis como la experimentada demuestran que en un gran número de casos la emergencia requerirá de una respuesta homogénea en el territorio nacional (el virus no conoce de delimitaciones administrativas), sin que quepa, además, ignorar la existencia de determinados límites y principios constitucionales que así lo exijan. La articulación de órganos de coordinación en donde tengan asiento todas las Administraciones implicadas debe saludarse como un dato positivo, pero ello debe ir acompañado con una explicitación clara de asunción de responsabilidades, de rango de las normas que afecten a derechos y libertades así como de publicidad de las mismas (aspectos todos ellos que se han visto "menguados" en la reciente y actual crisis del covid-19). Por otra parte, en los casos permitidos de designación de los Presidentes de las Comunidades Autónomas como autoridades delegadas ha de explicitarse un régimen de control parlamentario con las debidas garantías (a este respecto, ha llegado a sugerirse, con ocasión de la pandemia del covid-19, que en tales supuestos es el Congreso de los Diputados quien debe ejercer tal control, cuestión no exenta de cierta dificultades desde el punto de vista constitucional, y que, en cualquier caso, debiera aparecer explicitado en la LO 4/1981 y en el Reglamento de la Cámara Baja). 
En relación con las Comunidades Autónomas, cabe recordar que dos procesos electorales autonómicos (el gallego y el vasco) debieron ser suspendidos 0 aplazados como consecuencia de la pandemia. Sin perjuicio de que la solución alcanzada fuera la única (o en todo caso, la más) razonable, ello ha puesto de manifiesto la necesidad de una previsión expresa para supuestos como el acaecido, ante el vacío actualmente existente. En este sentido, ha de tenerse en cuenta que nuestra legislación en materia de referéndums sí contiene una previsión al respecto ${ }^{41}$, disponiendo la prohibición de celebración de los mismos durante la vigencia de los estados de excepción y sitio (y hasta los 90 días siguientes a su finalización $)^{42}$. Tal solución no fue trasplantada al ámbito electoral, dado que pesó más en esta ocasión el temor a que el ejecutivo de turno (también el legislativo) pudiera evitar la cita con las urnas mediante el recurso abusivo o improcedente, en su caso, a la declaración de un estado excepcional. Con todo, lo cierto es que situaciones como la vivida han puesto sobre la mesa la conveniencia de que en determinadas coyunturas no tenga lugar la celebración de elecciones (ante la ausencia de las debidas garantías) ${ }^{43}$, si bien se trata de una cuestión sumamente delicada pues no siempre sería fácil deslindar cuando nos hallásemos ante una situación que, no sólo justifique, sino que haga casi obligado el aplazamiento de la elección, y cuando no. La exigencia para tal aplazamiento de un acuerdo con el apoyo de una amplia mayoría de las Cámaras implicadas (esto es, aquellas llamadas a renovarse), que bien pudiera ser de $3 / 5$ o 2/3 de sus miembros, podría ser una solución razonable en tales $\operatorname{casos}^{44}$. Junto a ello, o bien como alternativa,

\footnotetext{
${ }^{41}$ Artículo 4.1 de la Ley Orgánica 2/1980, de 18 de enero, sobre regulación de las distintas modalidades de referéndum.

42 Precisamente, el hecho de que la LO 2/1980 únicamente impida la celebración de referéndums vigentes los estados de excepción o sitio, y permitiéndolos en cambio en el de alarma, no haría sino confirmar que la situación vivida en nuestro país, y que determinó el aplazamiento de las elecciones autonómicas gallegas y vascas, se correspondía con la propia de un estado de excepción (o dicho de otro modo, si durante el estado de alarma el legislador orgánico permite la celebración de referéndums, prohibiéndolos bajo el de excepción, de aceptarse la posibilidad de aplazar procesos electorales ello únicamente estaría permitido en los estados de excepción y sitio).

${ }^{43}$ Posición que ya se mantenía hace unos años por el autor de estas líneas ("Comentario al art.4 de la Ley Orgánica de Referéndum", en Comentarios a la Ley Orgánica del Régimen Electoral General y a la Ley Orgánica de Referéndum (DELGADO-IRIBARREN, M., coord.). La Ley, 2014, pp.1805-6.

${ }_{44}$ Puede traerse a colación al respecto la previsión contenida en la Ley Fundamental de Bonn (art. $115 \mathrm{~h}$. 1.) por la que, agotado el mando de las Cámaras federales o estatales durante la vigencia del estado de defensa, las elecciones consiguientes se celebrarán a los seis meses de la finalización de la vigencia de tal estado, cabiendo recordar que la declaración de tal estado ha de hacerse con la aprobación del Bundestag mediante mayoría de 2/3 que represente al menos la mayoría absoluta del mismo (por otra parte, y este caso al igual que sucede en España, no se admite la disolución "anticipada" durante el estado de defensa).
} 
podría requerirse dictamen conforme del Tribunal Constitucional y/o de la Junta Electoral Central. En cualquier caso, si bien para el referéndum la limitación referida con anterioridad no se estableció en sede constitucional, lo cierto es que para los supuestos de aplazamiento de elecciones a órganos representativos (nacionales o autonómicos) aparece como necesaria una reforma de la Constitución, y posiblemente también de los Estatutos de Autonomía, que previera los supuestos señalados (con una regulación más detallada en la LOREG).

Un aspecto que no requeriría reforma constitucional, y que se antoja como de la máxima relevancia y pertinencia dada nuestra experiencia reciente, es el del necesario establecimiento de un recurso especial de inconstitucionalidad (distinto del general) ante el Tribunal Constitucional frente a las disposiciones, con fuerza de ley, por las que se declaran o prorrogan cualquiera de los estados excepcionales contemplados en el artículo 116 de la Constitución. Se trataría de un recurso tramitado por un procedimiento específico de urgencia, semejante al previsto para el supuesto del denominado recurso de amparo electoral, que cuenta, como es sabido, con plazos muy perentorios de tramitación y resolución ${ }^{45}$ (se aplicaría también a las cuestiones de inconstitucionalidad planteadas en relación con las disposiciones señaladas). Precisamente, el que transcurrido ya más de medio año desde que se interpusiera el primer recurso contra la declaración del estado de alarma, el máximo intérprete de nuestra Constitución no se haya pronunciado sobre el mismo es un hecho cuando menos llamativo, ahorrándonos cualquier otro calificativo. Si precisamente existe alguna situación en la que el Tribunal Constitucional haya de pronunciarse con la máxima celeridad y urgencia sobre un asunto, este no es otro que la respuesta que desde los poderes públicos (ejecutivo y legislativo) se dé ante una emergencia como la vivida, máxime cuando, como ha sido y es el caso, se ven afectados de una manera particularmente intensa los derechos y libertades del conjunto de ciudadanos.

Pero sin duda alguna el aspecto que más intensamente reclamaría una modificación de nuestra LO 4/1981 es el atinente a la acomodación del presupuesto de hecho correspondiente a una crisis sanitaria como la provocada por la covid-19 y las medidas que pueden adoptarse para afrontar la misma. Se trataría, pues, de solventar la actual discordancia entre un

45 Dos días para su interposición, y tres días para su resolución por parte del Tribunal Constitucional, de acuerdo con lo dispuesto en el artículo 49.3 de la LOREG. 
presupuesto de hecho propio del estado de alarma y una respuesta, como la adoptada, propia del estado de excepción, situación que, como se señalara líneas más arriba, es aquella en la que precisamente ha vivido nuestro país a raíz de la pandemia mundial. Para ello, si no se quiere modificar Constitución, podría establecerse en la propia Ley Orgánica 4/1981 una subespecie del estado de excepción, el de excepción sanitaria o epidemiológica, o, si se mantiene el ya mencionado prurito que huye (incomprensiblemente, como ya se apuntó) de la denominación clásica, se sugiere la rúbrica "estado de emergencia sanitaria excepcional". De este modo, bajo ese nuevo "subestado" podrían adoptarse medidas que comportasen la suspensión general de derechos y libertades. En relación con ello, habría de aprovecharse la reforma para incluir en el elenco de posibles medidas a adoptar en el estado de excepción medidas tales como el confinamiento domiciliario, los llamados toques de queda, las burbujas de convivientes, etc... Igualmente, debiera acometerse con tal ocasión una regulación más exhaustiva (por no decir mínima, pues la actual es prácticamente "inexistente") del régimen de infracciones y sanciones en los supuestos señalados.

Por lo que respecta a la segunda de las vías señaladas, esto es, aquella que implique la reforma de nuestro texto constitucional, aquí las opciones son más amplias, por razones obvias. De este modo, podría reformarse el artículo 55.1 CE y permitir medidas que conlleven la suspensión de derechos y libertades para el supuesto de estado de alarma (o únicamente cuando el mismo venga motivado por una crisis sanitaria). Otra opción sería crear un nuevo estado excepcional, el de emergencia sanitaria, con medidas específicas que pudiesen comportar restricciones intensas o incluso la suspensión de determinados derechos y libertades. En ambos casos podría establecerse un régimen especial respecto a los plazos de duración de los mismos y sus prórrogas que difiera del régimen general (por ser más amplios) ${ }^{46}$. Por otra parte, podría optarse también por constitucionalizar de algún modo el papel de las Comunidades Autónomas en tales supuestos (por ejemplo, su rol como

\footnotetext{
${ }^{46}$ Un ejemplo interesante al respecto es el portugués, cuya Constitución, como se señaló con anterioridad, parte de una consideración gradualista de la excepción, estableciendo (art. 19.3) como presupuesto del estado de emergencia una alteración de la normalidad menos grave que la requerida para el de excepción (estableciéndose los mismos supuestos para ambos), y permitiendo también en aquel la suspensión de algunos derechos o libertades (con carácter más limitado que en el último). Asimismo, ha de señalarse que en relación con el estado de emergencia, la Norma Fundamental lusa no establece plazo de duración máxima, mientras que sí lo hace para el de excepción (15 días).
} 
autoridades delegadas), en cuyo caso quizás pudiera resultar conveniente la atribución de competencias de control al Senado.

En definitiva, hoy, tras varios meses de pesadilla mundial, es necesario proceder de manera urgente al aggiornamento de nuestro derecho de excepción. Este nunca más podrá ser una realidad ingrata a la que se prefiere no mirar, siendo tal actitud comparable a la de un derecho mercantil que no contemplara un derecho de quiebras o a una Medicina que no abordara las ramas más "escatológicas". La crisis sanitaria y, dada su amplitud, social, que hemos padecido (que aun padecemos en el momento en que se escriben estas líneas) llama una vez más a las puertas del Derecho para que, en medio de tanto dolor, asegure, como siempre, las soluciones y respuestas más razonables, más justas y más eficaces posibles. El ordenamiento español ha respondido con luces y sombras. Así, entre las primeras debe destacarse que, con todas las imperfecciones señaladas más atrás, permitió que en un ejercicio de responsabilidad y solidaridad protagonizado colectivamente se pudiera contener el flujo de vidas que se iban diariamente por un sumidero escalofriante. En el "debe" cabe subrayar que operábamos con instrumental de hace cuarenta años, nunca antes testado de este modo, y que, si bien ha revelado el acierto de contar con el mismo, también lo ha hecho en relación con los imprescindibles aspectos a mejorar, entre los que destacan la necesaria garantía de los derechos y la ponderación de medidas con los derechos e intereses de todo tipo, económicos entre ellos, eventualmente sacrificados. En la ineludible construcción del nuevo mañana habrá que contar necesariamente con la previsión de un "imposible" pasado mañana, que ojalá nunca llegue, pero cuya página, por más doloroso y difícil que resulte, ha de comenzar a escribirse hoy. 